\title{
Reestruturação dos serviços prestados em biblioteca universitária
}

\author{
Restructuring of services provided in university library \\ Tatiana Rossi ${ }^{1}$, William Barbosa Vianna ${ }^{2}$ \\ ${ }_{1}^{1}$ Programa de Pós-Graduação em Ciência da Informação, Universidade Federal de Santa Catarina, Florianópolis, SC, Brasil \\ ${ }^{2}$ Universidade Federal de Santa Catarina, Florianópolis, SC, Brasil
}

Autor para correspondência/Mail to: Tatiana Rossi, tat.caua@gmail.com

Financiamento/Funding: Fundação Araucária e Governo do Estado do Paraná

Copyright (c) 2018 Rossi \& Vianna. Todo o conteúdo da Revista (incluindo-se instruções, política editorial e modelos) está sob uma licença Creative Commons Atribuição-NãoComercial-Compartilhalgual 3.0 Não Adaptada. Ao serem publicados por esta Revista, os artigos são de livre uso em ambientes educacionais, de pesquisa e não comerciais, com atribuição de autoria obrigatória. Mais informações em http://revistas.ufpr.br/atoz/about/submissions\#copyrightNotice.

\begin{abstract}
Resumo
As bibliotecas universitárias precisam continuamente se inovar e manter a prestação de serviços essenciais aos seus usuários, e, considerando que as necessidades informacionais mudam tendo em vista as novas tecnologias, alterações de currículos de cursos, criação de novos cursos, inserções de novos projetos de pesquisa e extensão universitária, a reestruturação contínua dos serviços da biblioteca torna-se necessária. Para isso, tem-se como objetivo dessa pesquisa, reestruturar os serviços de Bibliotecas Universitárias. Serão identificadas as necessidades dos usuários no que concerne ao suporte em atividades relacionadas ao ensino, pesquisa e extensão por meio de questionário e entrevistas semiestruturadas; verificado, por meio de levantamento bibliográfico, as tendências e os serviços inovadores para bibliotecas universitárias; levantado, por meio de pesquisa documental os serviços prestados pelas bibliotecas; e, por fim, propor um modelo para reestruturação dos serviços apontando os que devem ser descontinuados e os que precisariam ser incluídos, além de conter um instrumento para acompanhamento dos serviços. Prevê-se, com a criação desse modelo, uma reestruturação dos serviços prestados a fim de que o capital humano e os recursos sejam redirecionados para serviços inovadores que sejam efetivos e garantam o atendimento das necessidades informacionais da comunidade acadêmica.
\end{abstract}

Palavras-chave: Serviços inovadores; Biblioteca universitária; Gestão estratégica.

\begin{abstract}
University libraries need to continually innovate and maintain essential services for their users, and considering that information needs change in the face of new technologies, changes in curricula of courses, creation of new courses, insertion of new research projects and university extension, the ongoing restructuring of library services becomes necessary. The objective of this research is to propose to restructure the services of University Libraries. Activities related to teaching, research and extension regarding support of users' needs will be identified through a questionnaire and semi-structured interviews. A bibliographical survey will verify trends and innovative services for university libraries; and will be raised the services provided by libraries through documentary research. Finally, a model for the restructuring of the services, pointing out the ones that should be discontinued and those that would need to be included will be propose, besides containing an instrument to monitor the services. In addition to this model, a restructure of provided services so that human capital and resources are redirected to innovative services that are effective and guarantee the information needs of the academic community.

Keywords: Innovative services; University library; Strategic management.
\end{abstract}

\section{INTRODUÇÃO}

As Bibliotecas Universitárias (BUs) colaboram na geração do conhecimento e dão suporte ao processo de ensino e aprendizagem desenvolvidos na universidade por meio de múltiplos serviços a fim de atender às mais diversas necessidades dos usuários.

Considerando que as necessidades da comunidade acadêmica tendem a mudar constantemente haja vista as novas tecnologias, alterações de currículos dos cursos, criações de novos cursos, inserções de novos projetos de pesquisa e extensão universitária, entre outras. Tanto a universidade, quanto a BU precisam continuamente se adequar.

Normalmente as BUs para compreender as necessidades dos usuários realizam o estudo de usuários. Porém, frequentemente este estudo não é aplicado de maneira rotineira e geralmente prevê a coleta do máximo de informações para tentar a readequação da biblioteca como um todo. O que se percebe é que o estudo acaba apresentando poucos elementos para subsidiar o encerramento de um serviço prestado que se encontra obsoleto ou mesmo explicitar, de forma clara, a real necessidade de implantação de outros serviços necessários.

Desse modo surge o seguinte questionamento: Como desenvolver serviços essenciais inovadores em bibliotecas universitárias?

As bibliotecas precisam continuamente se inovar e manter a prestação de serviços essenciais a seus usuários. Com isso, tem-se como objetivo geral desta pesquisa criar um modelo para reestruturação dos serviços de Bibliotecas Universitárias.

Como objetivos específicos pretende-se: 
a) identificar as necessidades dos usuários no que concerne ao suporte em atividades relacionadas ao ensino, pesquisa e extensão;

b) verificar na literatura as tendências e os serviços inovadores para bibliotecas universitárias;

c) verificar nas bibliotecas universitárias os serviços prestados;

d) propor um modelo para reestruturação dos serviços de BU;

e) validar o modelo na Universidade Federal de Santa Catarina.

Justifica-se a escolha dessa problemática com vistas ao desenvolvimento de uma tese que realize o estudo das necessidades atuais dos usuários para conhecer os serviços essenciais que uma BU precisaria realmente ofertar e prever sua implantação e constante remodelagem em virtude do contexto dinâmico em que se inserem.

A importância desta pesquisa reside no fato de considerar que os serviços ofertados pela biblioteca não podem ter um papel marginal na vida dos usuários e as bibliotecas devem conhecer as necessidades informacionais dos mesmos para aprimorar seus serviços de forma inovadora.

A relevância do estudo pauta-se no atendimento as necessidades dos usuários, o uso eficaz do capital humano e dos recursos disponibilizados pela instituição, além de propiciar competitividade à organização e ajudar no alcance dos objetivos institucionais.

A biblioteca possui como desafio satisfazer as necessidades e expectativas de um número crescente de estudantes, permanecendo dentro da realidade da biblioteca/universidade, com redução de recursos, com planejamento e gerenciamento cuidadoso para não aumentar a pressão sobre a equipe e tornar-se rapidamente insustentável (Phillips, 2016).

O interesse na temática em questão originou-se pela atuação da autora em Biblioteca Universitária e pela participação em vários eventos da área que, consequentemente, possibilitam a troca de experiências com os pares. Constatou-se que os serviços prestados nas universidades são convergentes e que alguns serviços se mantêm por sua tradição, embora se perceba o decréscimo de utilização e que outros serviços são identificados como necessários para os usuários e, embora relevantes, não são implantados.

\section{REVISÃO DE LITERATURA}

Contrariando o senso comum a biblioteca não deixou e não deixará de existir com o advento das tecnologias, embora precise se reinventar constantemente para atender as necessidades e expectativas dos usuários. Segundo Sampaio et al. (2004) quanto mais próximo das expectativas dos clientes maior é a qualidade dos serviços, mas outros fatores também são importantes para a prestação do serviço, como o de valorizar a oportunidade; que a quantidade não significa qualidade; que a informação atrasada é inútil; e, que as necessidades informacionais mudam com o passar do tempo (Borges, 2007).

Roberto Taylor em 1969 já dizia que uma biblioteca não poderia ser somente um armazém sofisticado, mas sim o centro para criação, uso e distribuição do conhecimento orientada para comunicação (Taylor, 1969 como citado em King, 2016). Atualmente o que se observa é uma evolução do potencial dos bibliotecários e serviços da biblioteca, pois, na antiguidade os bibliotecários eram guardiões do acervo e hoje passaram a ser responsáveis pelo acesso e pela disseminação da informação a partir de diferentes serviços prestados nos mais diversos suportes.

Para Silveira, Vianna e Cândido (2017) a inovação do tipo organizacional, a qual é a mais próxima da biblioteca, busca adotar iniciativas e boas práticas para melhorar o desempenho frente aos desafios e obter importantes insights para o fortalecimento de uma cultura de inovação.

Segundo Phillips (2016) as bibliotecas são afetadas pelas mudanças e respostas estratégicas institucionais, e, correspondentemente, as bibliotecas possuem planos orçamentários e número de pessoal reduzido, ao mesmo tempo em que ofertam serviços de alta qualidade que atendem e antecipam as necessidades de um número crescente de estudantes tornando-se cada vez mais complexas.

\section{Necessidade informacional}

As necessidades informacionais diferem para cada usuário, porém, há um padrão se pensarmos, por exemplo, nos alunos de graduação de um determinado curso, pesquisadores de um determinado centro de pesquisa. Para que a biblioteca possa ofertar serviços de informação, é válido ter o conhecimento desses padrões dentro da universidade em que atua.

Martínez-Silveira e Oddone (2007, p. 122) relatam que "influenciadas principalmente por fatores pessoais, as necessidades informacionais apresentam características mais gerais quando analisadas por grupos de usuários, uma vez que as particularidades e o contexto de cada grupo podem determinar certo padrão". E que, diferentemente de outros profissionais, os quais "são especialistas do assunto sobre o qual seu cliente é 'ignorante', o profissional 
da informação tem um cliente que é um especialista em sua própria área”, o que requer maior destreza desse profissional no atendimento as suas necessidades informacionais.

Line (1974, como citado em Figueiredo, 1994, p. 34) menciona que necessidade é "o que um indivíduo deve ter para o seu trabalho, pesquisa, edificação, recreação etc." complementa que "necessidade é usualmente concebido como uma contribuição para uma finalidade séria, não frívola". E por fim que "uma necessidade é uma demanda em potencial".

Para sintetizar os conceitos sobre necessidade de informação levantados por Martínez-Silveira e Oddone (2007, p. 122) as autoras apontam que apenas dois podem ser identificados com segurança, sendo o primeiro de "que há sempre implícito um motivo ou propósito" e que é a "sua natureza de processo cognitivo, que diferenciaria as necessidades informacionais das fisiológicas, por exemplo".

Martínez-Silveira e Oddone (2007, p. 122) lembram ainda que foi a partir dos anos 1980 que os estudos passaram a valorizar a perspectiva do usuário enfatizando-o na transferência da informação. Costa (2016, p. 97) apresenta que "a valorização do usuário se faz obrigatória, sendo o conhecimento dele o ponto de partida para tomadas de decisão das instituições e respectivos processos de mudança, crescimento e inovação".

\section{Serviços}

As bibliotecas, como parte integrante das Instituições de Ensino Superior (IES) são as prestadoras de serviços em que se visa o acesso e o uso da informação por toda a comunidade acadêmica. Para Santos, Fachin e Varvakis (2003) os serviços não são palpáveis, são intangíveis e de difícil mensuração. Segundo Dias e Belluzzo (2003) o serviço tem alto grau de incerteza e vulnerabilidade, variabilidade, complexidade de produção e é impossível de armazenar.

Segundo Tarapanoff, Araujo e Cormier (2000, p. 92):

As unidades de informação (bibliotecas, centros e sistemas de informação e de documentação) foram e são, tradicionalmente, organizações sociais sem fins lucrativos, cuja característica como unidade de negócio é a prestação de serviços, para os indivíduos e a sociedade, de forma tangível (produtos impressos), ou intangível (prestação de serviços personalizados, pessoais, e hoje, cada vez mais, de forma virtual - em linha, pela Internet).

Embora Silva (2006) e Partridge, Menzies, Lee \& Munro (2010) considerem que a visão da Biblioteca permanece a mesma: "prestar serviços que atraiam os usuários", na verdade o que se anuncia é uma mudança nas ferramentas utilizadas pelos bibliotecários que nelas atuam (Villa Barajas \& Alfonso Sánchez, 2005; Partridge et al., 2010).

As bibliotecas prestam diversos serviços, e com as novas tecnologias, a globalização e, em especial, com a valorização da informação, passaram a ter novas demandas de serviço e aumento da utilização de recursos digitais para acesso de conteúdos pela Internet.

Cunha (2000, p. 75) apresenta a evolução tecnológica da biblioteca passando de uma era "tradicional moderna", para "automatizada", "eletrônica", "digital" e agora, "virtual". Comenta que ao menos "[...] nos últimos 150 anos, as bibliotecas sempre acompanharam e venceram os paradigmas tecnológicos". Contudo, não se pode esquecer que as BUs são vistas como "[...] centros de custos, e não de captação de recursos. [...]" (Cunha, 2000, p. 72), portanto, precisam mostrar seu potencial e a relevância no mundo acadêmico, sendo que o seu valor será medido, por exemplo, pela capacidade de prover o acesso à informação em todos os tipos de formatos disponíveis e alinhamento aos objetivos estratégicos institucionais. Cunha (2000) observa ainda que os universitários da geração digital esperam e desejam maior interação, pois aprendem por meio de participação e experimentação direta.

Jianzhong and Chen (2013) apontam três fatores que impactaram as bibliotecas nos últimos 30 anos: em meados de 1980 com o crescimento da Internet pela combinação do uso do computador, informação e tecnologias de comunicação; na virada do século XXI pelo desenvolvimento da Internet e o aumento da informação eletrônica; e o terceiro, recentemente, com o uso do meio digital contrapondo o tradicional uso do papel.

Sputore, Humphries and Steiner (2015) colocam que, como os usuários se tornaram mais on-line, alguns serviços foram criados como os guias on-line para novos tipos de recurso e a antecipação de perguntas no Frequently Asked Questions (FAQ) on-line. O apoio tornou-se onipresente fazendo com que os usuários encontrem a informação por conta própria, mas acrescenta um efeito colateral de que, dessa forma, ocorre também o desaparecimento aparente (desintermediação) dos bibliotecários na perspectiva dos usuários.

Freitas, Bolsanello e Viana (2008, p. 91) apresentam os serviços que passaram a ser disponibilizados aos usuários devido à evolução da tecnologia da informação, como:

[...] serviço de reserva de livros pela Internet, [...] o serviço de consulta à base de dados das bibliotecas (consulta ao acervo realizada in loco ou pela Internet, utilizando recursos de busca por título, por autor, por palavras-chave etc.), consulta ao Portal de Periódicos da Coordenação de 
Aperfeiçoamento Pessoal de Nível Superior (Capes) e também o acesso à Internet para fins de pesquisa. Vale ressaltar também que nos últimos anos as dissertações de mestrado e teses de doutorado têm sido disponibilizadas em formato digital [...].

Embora cada BU seja livre para prestar os serviços que melhor atendam a sua demanda, necessidades e objetivos estratégicos institucionais, eles são convergentes, havendo pequenas variações, como pode ser observado no estudo de Rossi (2012) referente às bibliotecas de universidades da grande Florianópolis (Quadro 1):

\begin{tabular}{|c|c|c|c|}
\hline UDESC & UNISUL & UNIVALI & UFSC \\
\hline Acesso à bases de dados & Acesso usuário & Ação cultural & $\begin{array}{l}\text { Acessibilidade Informaci- } \\
\text { onal - AAI }\end{array}$ \\
\hline $\begin{array}{l}\text { Atividades artísticas e } \\
\text { culturais }\end{array}$ & Aquisição & Acesso à internet & Aquisições \\
\hline $\begin{array}{l}\text { Banco Digital de Teses da } \\
\text { UDESC }\end{array}$ & Boletim novas aquisições & Biblioteca virtual & $\begin{array}{l}\text { Auditórios, laboratórios e } \\
\text { espaço cultural }\end{array}$ \\
\hline $\begin{array}{l}\text { Biblioteca Digital da } \\
\text { UDESC }\end{array}$ & $\begin{array}{l}\text { Cadastro áreas de inte- } \\
\text { resse }\end{array}$ & Capacitação de usuários & Bases de dados - Saber \\
\hline $\begin{array}{l}\text { Boletim de sumários cor- } \\
\text { rentes }\end{array}$ & Cadastro na Biblioteca & Comutação bibliográfica & Bookmark \\
\hline $\begin{array}{l}\text { Catalogação na publica- } \\
\text { ção / ficha catalográfica }\end{array}$ & Capacitações de usuários & $\begin{array}{l}\text { Consulta em bases de da- } \\
\text { dos }\end{array}$ & BU Informa \\
\hline $\begin{array}{l}\text { Comutação Bibliográfica } \\
\text { - COMUT }\end{array}$ & Comutação bibliográfica & Consulta local & Catalogação na Fonte \\
\hline Consulta local & Empréstimos & $\begin{array}{l}\text { Consulta } \\
\text { acervo }\end{array}$ & Comutação Bibliográfica \\
\hline $\begin{array}{l}\text { Divulgação de novas aqui- } \\
\text { sições e serviços }\end{array}$ & Ficha catalográfica & $\begin{array}{l}\text { Elaboração de fichas; } \\
\text { Catalográficas institucio- } \\
\text { nais }\end{array}$ & Conheça a Biblioteca \\
\hline Empréstimo domiciliar & $\begin{array}{l}\text { Orientação Bases de Da- } \\
\text { dos }\end{array}$ & Empréstimo domiciliar & Dissertações/Tese/TCC \\
\hline Intercâmbio bibliotecário & $\begin{array}{ll}\text { Orientação } & \text { Trabalhos } \\
\text { acadêmicos } & \end{array}$ & $\begin{array}{l}\text { Empréstimo entre biblio- } \\
\text { tecas do Sibiun e exter- } \\
\text { nas }\end{array}$ & $\begin{array}{l}\text { Empréstimo entre biblio- } \\
\text { tecas }\end{array}$ \\
\hline ISBN & Renovação & $\begin{array}{l}\text { Laboratórios de informá- } \\
\text { tica }\end{array}$ & Ensino a distância - EAD \\
\hline ISSN & Reserva & $\begin{array}{l}\text { Levantamento bibliográ- } \\
\text { fico }\end{array}$ & Espaço digital \\
\hline $\begin{array}{l}\text { Levantamento bibliográ- } \\
\text { fico }\end{array}$ & Visita orientada & Orientação bibliográfica & ISSN - ISBN \\
\hline $\begin{array}{l}\text { Normalização bibliográ- } \\
\text { fica }\end{array}$ & & $\begin{array}{l}\text { Renovação e reserva on- } \\
\text { line }\end{array}$ & MORE \\
\hline $\begin{array}{l}\text { Serviço de Disseminação } \\
\text { Seletiva da Informação }\end{array}$ & & Serviço de referência & $\begin{array}{l}\text { Normalização de traba- } \\
\text { Ihos }\end{array}$ \\
\hline $\begin{array}{l}\text { Treinamento para a utili- } \\
\text { zação bases dados }\end{array}$ & & $\begin{array}{l}\text { Serviço integrado de de- } \\
\text { volução }\end{array}$ & Nossos formulários \\
\hline \multirow[t]{4}{*}{ Visita orientadas } & & Visitas orientadas & Programa de capacitação \\
\hline & & & Redes corporativas \\
\hline & & & Sala verde \\
\hline & & & WEB TV \\
\hline
\end{tabular}

Quadro 1. Serviços prestados nas bibliotecas de universidades da grande Florianópolis

Fonte: Rossi (2012, p. 161-162).

Nota 1: Serviços marcados em negrito se repetem em ao menos duas bibliotecas. Serviços marcados em negrito e itálico se repetem em todas as bibliotecas, embora alguns tenham nomes um pouco diferenciados.

Nota 2: Alguns citados, embora constassem no site das universidades como serviços, não podem ser caracterizados como tal, por exemplo, Nossos Formulários.

Nota 3: Em 2018, os serviços se mantêm praticamente iguais e optou-se por trazer, nesse momento, o que já havia sido publicado para melhor recuperação da fonte.

As BUs procuram ofertar, além de serviços que forneçam suporte ao ensino, à pesquisa e à extensão, serviços que promovam o desenvolvimento cultural e social do usuário porque as necessidades deles ultrapassam o ambiente acadêmico, exemplos podem ser observados nas bibliotecas da grande Florianópolis: "Atividades artísticas e culturais"/"Acesso cultural"/"Auditórios, laboratórios e espaço cultural", "Espaço digital"/"Laboratório de informática"/"Acesso digital", entre outros. 


\section{Tendências nos serviços}

É positivo acompanhar as tendências e discussões para continuamente inovar nos serviços e produtos das bibliotecas. Um mapeamento das tendências relevantes para as bibliotecas e para a área de biblioteconomia é realizado constantemente pelo Center for the Future of Libraries da American Library Association [ALA] (2017), sendo que as atualizações são feitas à medida que relatórios e artigos são publicados. O compilado auxilia as bibliotecas e bibliotecários a entenderem como as tendências estão se desenvolvendo e a importância delas. Essas tendências estão organizadas em sete categorias, na qual cada cor codifica as classificações apresentadas na Figura 1, sendo elas: Sociedade (vermelho), Tecnologia (azul claro), Educação (azul escuro), Meio Ambiente (verde) Política e governo (laranja), Economia (roxo) e Demografia (amarelo):

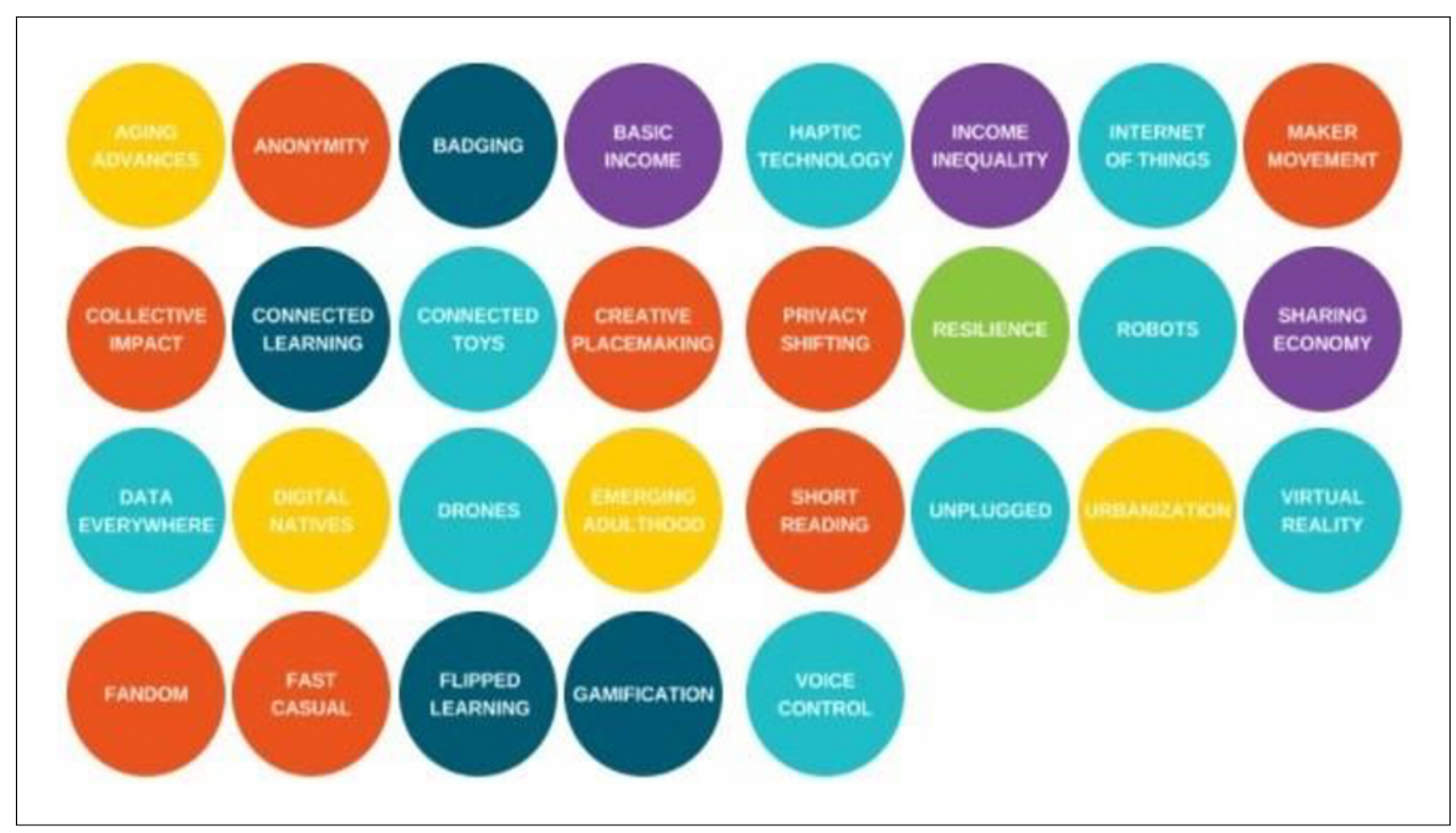

Figura 1. Classificação das tendências do Centro para Futuro das Bibliotecas da ALA

Fonte: American Library Association (2017)

A Association of College $\&$ Research Libraries [ACRL] (2017) publica a cada dois anos as principais tendências para as BUs, a última revisão foi feita em 2016 e apresentou:

a) serviços de dados de pesquisa;

b) políticas de dados e gestão de dados de pesquisa;

c) desenvolvimento profissional para bibliotecários que oferecem os serviços de dados de pesquisa;

d) academia digital (centros de pesquisas digitais);

e) tendências de avaliação de coleção;

f) fusões de provedores de conteúdo;

g) evidência de aprendizagem: sucesso do aluno, aprendizagem analítica e acreditação;

h) novas orientações com o Estrutura de Competência em Informação para o Ensino Superior;

i) competência informacional crítica no Framework;

j) altimetria;

k) perfis profissionais emergentes;

l) recursos educacionais abertos (REA).

Em setembro de 2017 houve um evento nacional, sediado em Florianópolis/Santa Catarina, com foco nas tendências apresentadas pela ACRL, o "I Seminário de Suporte à Pesquisa e Gestão de Dados Científicos: panorama atual e desafios", a fim de reunir práticas já existentes de apoio à pesquisa e gestão de dados de pesquisa e os desafios para implementação de serviços dessa natureza no Brasil (Seminário de Suporte à Pesquisa e Gestão de Dados Científicos: panorama atual e desafios, 2017). 
Recentemente tem havido foco das bibliotecas no apoio às áreas especializadas que requerem serviços mais elaborados e dispendiosos, porém, serviços sustentáveis, colaborativos e para aprendizagem organizacional também estão em voga.

\section{Serviços sustentáveis e inovadores}

Weber $(2011$, p. 493, 495) aponta que "ao pensarmos a biblioteca como um organismo vivo, dinâmico e crescente, é possível pensá-la como alicerçada nas diretrizes que norteiam a sustentabilidade" e conseguimos perceber que:

[...] as bibliotecas, atendem aos princípios de sustentabilidade, ao disponibilizar seus serviços e formações. Quando buscam ser referencia em inovação, recuperação, preservação e disseminação da informação, participam do desenvolvimento do individuo e logo de forma sustentável e participativa, pois integram a sustentabilidade econômica, ambiental, espacial, social e cultural, coletivas ou individuais, visando o alcance e a manutenção da qualidade de vida, e tendo como perspectivas a cooperação e a solidariedade entre as pessoas, em diferentes gerações.

Para Alves (2017) as bibliotecas, com sua função social ofertam o empréstimo domiciliar sem custo, promovem exposições e eventos gratuitos, propiciam acesso a equipamentos informáticos e à Internet, realizam esforços para proteger e salvaguardar o patrimônio cultural local, nacional e mundial, proporcionam acesso a espaços públicos seguros, inclusivos, acessíveis e contribuem permanentemente para os espaços de reflexão.

Outros autores apresentam serviços sustentáveis e inovadores como o empréstimo de sacola retornável para o acondicionamento dos materiais bibliográficos emprestados (Peixoto \& Barcellos, 2016), uso dos portais gerenciadores de periódicos como o OJS/SEER e a participação da Rede Brasileira de Preservação Digital Cariniana (Santos, 2016), sala de videoconferência para atender defesas, qualificações, aulas e eventos; elaboração de tutoriais para capacitação de alunos de graduação e pós-graduação; utilização da ferramenta Moodle para gerenciamento de disciplinas/capacitações; adoção de mídias sociais para comunicação; Biblioteca Digital de trabalhos acadêmicos, teses e dissertações; criação de templates para elaboração de trabalhos acadêmicos, eliminação de recibos de empréstimo e devolução os quais são enviados por e-mail; entre outros (Coletta, Silva \& Cassin, 2016), o recebimento de livros de literatura por meio da troca de multas decorrentes de atraso na devolução de livros para atualizar o acervo da biblioteca (Ribeiro et al., 2016), ou mesmo destinando os bibliotecários para concentrar-se em áreas específicas do conhecimento dando suporte à pesquisa, aprendizagem ou ensino, mas no início do semestre se concentrando nos programas de aprendizagem com picos de demandas (Phillips, 2016).

Sabe-se também de atividades internas como a comunidade de prática e comissões de trabalho que são boas formas de aprendizagem sustentável pela troca de conhecimentos e direcionamento das necessidades internas da biblioteca. Sem contar que a "dinâmica da inovação está fortemente associada à utilização do conhecimento disponível e aproveitamento de oportunidades tecnológicas e de mercado" (Cândido, 2015, p. 25).

A aprendizagem sustentável leva as pessoas a interagirem participando em situações que agregam conhecimentos, o que facilita no acompanhamento da evolução das necessidades dos usuários mantendo os serviços e/ou criando novos.

\section{METODOLOGIA}

Para atender aos objetivos dessa pesquisa far-se-á:

a) pesquisa documental para verificar nas bibliotecas universitárias os serviços prestados;

b) pesquisa bibliográfica para verificar na literatura as tendências e os serviços inovadores para bibliotecas universitárias;

c) coleta de dados por meio de entrevista semiestruturada com os dirigentes da instituição (diretores de centro, coordenadores de curso, de pesquisa e extensão) e aplicação de questionário com os demais membros da comunidade universitária a fim de identificar as necessidades dos usuários com relação ao suporte ensino, pesquisa e extensão.

A partir de então será proposto um modelo para reestruturação dos serviços apontando aqueles que deveriam ser descontinuados daqueles que necessitam ser incluídos como serviços inovadores. Este modelo conterá também um instrumento para acompanhar os serviços a fim de que se mantenham atuais e atendendo as necessidades e expectativas dos usuários. Por fim, será validado o modelo na Universidade Federal de Santa Catarina.

Tem-se como previsão para o desenvolvimento do projeto de pesquisa as etapas constantes no quadro a seguir. 


\begin{tabular}{|l|c|c|c|c|c|c|c|c|}
\hline Atividade & $2018 / 1$ & $\mathbf{2 0 1 8 / 2}$ & $\mathbf{2 0 1 9 / 1}$ & $\mathbf{2 0 1 9 / 2}$ & $\mathbf{2 0 2 0 / 1}$ & $\mathbf{2 0 2 0 / 2}$ & $\mathbf{2 0 2 1 / 1}$ & $\mathbf{2 0 2 1 / 2}$ \\
\hline Pesquisa bibliográfica & $\mathrm{X}$ & $\mathrm{X}$ & $\mathrm{X}$ & & & & & \\
\hline Pesquisa documental & & $\mathrm{X}$ & $\mathrm{X}$ & & & & & \\
\hline Coleta de dados & & & $\mathrm{X}$ & & & & & \\
\hline Análise dos dados & & & $\mathrm{X}$ & $\mathrm{X}$ & $\mathrm{X}$ & & & \\
\hline Qualificação & & & & $\mathrm{X}$ & & & & \\
\hline Elaboração do modelo & & & & & $\mathrm{X}$ & $\mathrm{X}$ & & \\
\hline Validação do modelo & & & & & & & $\mathrm{X}$ & \\
\hline Redação final da tese & & & & & & & $\mathrm{X}$ & $\mathrm{X}$ \\
\hline Defesa & & & & & & & & $\mathrm{X}$ \\
\hline
\end{tabular}

Quadro 2. Cronograma com as principais atividades para o desenvolvimento do projeto de pesquisa Fonte: Elaborado pelos autores (2018).

\section{CONSIDERAÇÕES PARCIAIS}

Ao final do processo desta pesquisa pretende-se ter um modelo para reestruturação dos serviços de BU de forma a prestar serviços essenciais aos usuários. Dessa forma, prevê-se que o capital humano e os recursos sejam redirecionados para serviços inovadores que sejam efetivos e garantam o atendimento das necessidades informacionais da comunidade universitária.

Para além da instituição, ampliar as pesquisas e construir um diálogo conceitual sobre serviços obsoletos e essenciais ofertados nas bibliotecas universitárias e metodologia para avaliação dos serviços considerando a dinamicidade desse tipo de organização.

\section{AGRADECIMENTOS}

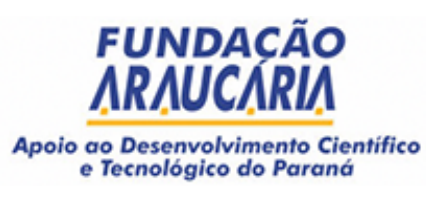

FUNDACÃO

Apoio ao Desenvolvimento Cientifico

e Tecnológico do Parana

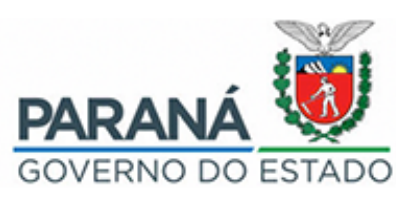

À Fundação Araucária e ao Governo do Estado pelo apoio financeiro para a realização do evento.

\section{REFERÊNCIAS}

Alves, A. (2017). O desenvolvimento sustentável e as bibliotecas. Correio do Minho, Braga. Recuperado de http://www.correiodominho.com/cronicas.php?id=8206

American Library Association. (2017). Center for the Future of Libraries. Library of the Future. Trends. Recuperado de http://www.ala.org/tools/future/trends

ACRL Research Planning and Review Committee. (2016). 2016 top trends in academic libraries: A review of the trends and issues affecting academic libraries in higher education. College \& Research Libraries News, 77(6), 274-281. doi: $10.5860 / \operatorname{crln} .77 .6 .9505$

Borges, M. E. N. (2007). O essencial para a gestão de serviços e produtos de informação. Revista Digital de Biblioteconomia e Ciência da Informação, 5 (1), 115-128. Recuperado de https://periodicos.sbu.unicamp.br/ojs/in dex.php/rdbci/article/view/2007

Cândido, A. C. (2015). Identificação das práticas de inovação aberta nas parcerias estratéficas: avaliação realizada com prestadores de cloud computing. Tese de doutorado, Universidade Nova de Lisboa, Lisboa. Recuperado de https://run.unl.pt/bitstream/10362/14833/1/Candido_2015.pdf

Coletta, T. G., Silva, E. G., \& Cassin, F. H. (2016). Sustentabilidade em serviços: ações da Biblioteca da EESC/USP. In Anais do Seminário Nacional de Bibliotecas Universitárias, Manaus: UFAM.

Costa, M. F. O. (2016). Estudos de usuários: aspectos teórico-conceituais. In M. F. O. Costa. Estudos de usuários da informação: ensino e aprendizagem no Brasil. Fortaleza: Edições UFC, pp. 51- 103.

Cunha, M. B. (2000). Construindo o futuro: a biblioteca universitária brasileira em 2010. Ciência da Informação, 29(1), 71-89. Recuperado de http://www.scielo.br/pdf/ci/v29n1/v29n1a8.pdf

Dias, M. M. K., \& Belluzzo, R. C. B. (2003). Gestão da informação em ciência e tecnologia sob a ótica do cliente. Bauru: EDUSC.

Figueiredo, N. M. (1994). Estudos de uso e usuários da informação. Brasília: IBICT. 
Freitas, A. L. P., Bolsanello, F. M. C., \& Viana, N. R. N. G. (2008). Avaliação da qualidade de serviços de uma biblioteca universitária: um estudo de caso utilizando o modelo Servqual. Ciência da Informação, 37(3), 88- 102. Recuperado de https://dx.doi.org/10.1590/S0100-19652008000300007

Jianzhong, W. \& Chen, X. (2013). Transition and transcendence: the innovative development of Shanghai Library. Library Management, 34(1/2), 20-30. Recuperado de https://www.emeraldinsight.com/doi/pdfplus/10.1108 /01435121311298243

King, J. G. (2016). Extended and experimenting: library learning commons service strategy and sustainability. Library Management, 37(3/4), 265-274. Recuperado de http://www.emeraldinsight.com/doi/pdfplus/10.1108 /LM-04- 2016-0028

Martínez-Silveira, M. \& Oddone, N. (2007). Necessidades e comportamento informacional: conceituação e modelos. Ciência da Informação, 36 (2), 118-127. Recuperado de http://www.scielo.br/pdf/ci/v36n2/12.pdf

Partridge, H. L., Menzies, V., Lee, J. M., \& Munro, C. (2010). The contemporary librarian: skills, knowledge and attributes required in a world of emerging technologies. Library and Information Science Research, 32(4), 265-271. Recuperado de http://eprints.qut.edu.au/37997/1/c37997.pdf

Peixoto, D. C., \& Barcellos, M. S. (2016). Empréstimo de sacola retornável junto aos livros numa biblioteca universitária do Espírito Santo: relato de experiência. In Anais do Seminário Nacional de Bibliotecas Universitárias, Manaus: UFAM.

Phillips, A. (2016) Educating at scale: sustainable library learning at the University of Melbourne. Library Management, 37(3), 149-161. Recuperado de http://www.emeraldinsight.com/doi/pdfplus/10.1108/LM04-2016- 0020

Ribeiro, R. M. R., Oliveira, G. M. T. de, Rocha, S. dos S., Ferreira, M. do C. S. B., \& Santana, I. C. N. (2016). Projeto Negociação Solidária: gestão sustentável do acervo. In Anais do Seminário Nacional de Bibliotecas Universitárias, Manaus: UFAM.

Rossi, T. (2012). Gestão de competências na prestação de serviços de informação em bibliotecas de universidades da região de Florianópolis. Dissertação de mestrado, Universidade Federal de Santa Catarina, Florianópolis.

Sampaio, M. I. C., Fontes, C. de A., Rebello, M. A. de F. R., Zani, R. M. F., Barreiros, A. de A., Prado, A. M. M. da C., ... Netto, A. C. (2004). PAQ - Programa de avaliação da qualidade de produtos e serviços de informação: uma experiência no SIBi/USP. Ciência da Informação, Brasília, 33 (1), 142-148.

Santos, G. C. (2016). Sustentabilidade e visibilidade da produção científica: a construção do Portal de Periódicos Eletrônicos Científicos da Unicamp. In Anais do Seminário Nacional de Bibliotecas Universitárias, Manaus: UFAM.

Santos, L. C., Fachin, G. R. B., \& Varvakis, G. (2003). Gerenciando processos de serviços em bibliotecas. Ciência da Informação, 32(2), 85-94. Recuperado de http://revista.ibict.br/ciinf/article/view/1009

Seminário de Suporte à Pesquisa e Gestão de Dados Científicos: panorama atual e desafios. (2017). Florianópolis: UFSC. Recuperado de http://seminariosuportepesquisa.ufsc.br/

Silva, C. C. M. (2006). O perfil do bibliotecário de referência das bibliotecas universitárias do estado de Santa Catarina. Dissertação de mestrado, Universidade Federal de Santa Catarina, Florianópolis. Recuperado de http://www.tede.ufsc.br/teses/PCIN0014.pdf

Silveira, M. M. \& Vianna, W. B \& Cândido, A. C. (2017). Fundamentos conceituais para abordagens de gestão da inovação em bibliotecas. Biblios: revista de biblioteconomia e Ciência da Informação,68, 69-81. Recuperado de http://www.scielo.org.pe/pdf/biblios/n68/a05n68.pdf

Sputore, A., Humphries, P., \& Steiner, N. (2015). Sustainable academic libraries in Australia: exploring 'radical collaborations' and implications for reference services. In Proceedings of World Library And Information Congress. Cidade do Cabo. Recuperado de http://library.ifla.org/id/eprint/1078

Tarapanoff, K., Araújo, R. H., Jr., \& Cormier, P. M. J. (2000). Sociedade da informação e inteligência em unidades de informação. Ciência da Informação, 29(3), 91-100. Recuperado de http://revista.ibict.br/ciinf/article/vi ew/876

Villa Barajas, H. \& Alfonso Sánchez, I. R. (2005). Biblioteca híbrida: el bibliotecario en medio del tránsito de lo tradicional a lo moderno. ACIMED, 13(2). Recuperado de http://eprints.rclis.org/6474/

Weber, C. (2011). As bibliotecas e o aporte para o desenvolvimento sustentável. In Congresso Internacional Responsabilidade e Reciprocidade: valores sociais para uma economia sustentável. Recanto Maestro: Faculdade Antonio Meneghetti. Recuperado de https://reciprocidade.emnuvens.com.br/rr/article/view/64/62 